\title{
J

\section{Nitric Oxide Is Reduced to HNO by Proton-Coupled Nucleophilic Attack by Ascorbate, Tyrosine, and Other Alcohols. A New Route to ${ }_{3} \mathrm{HNO}$ in Biological Media?}

\author{
${ }_{4}$ Sebastián A. Suarez, ${ }^{\dagger}$ Nicolás I. Neuman, ${ }^{\dagger \dagger}$ Martina Muñoz, ${ }^{\dagger}$ Lucia Alvarez, ${ }^{\dagger}$ Damián E. Bikiel, ${ }^{\dagger}$ \\ ${ }_{5}$ Carlos Brondino, ${ }^{\ddagger}$ Ivana Ivanović-Burmazović, ${ }^{\S}$ Jan Lj. Miljkovic, ${ }^{\S}$ Milos R. Filipovic, ${ }^{\S}$ \\ 6 Marcelo A. Martí, ${ }^{, \dagger, \perp}$ and Fabio Doctorovich $*^{\dagger}$ \\ 7 Departamento de Química Inorgánica, Analítica y Química Física, Facultad de Ciencias Exactas y Naturales, Universidad de Buenos \\ 8 Aires, Ciudad Universitaria/INQUIMAE-CONICET, Buenos Aires, Argentina

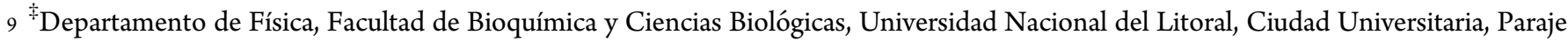 \\ 10 El Pozo, Santa Fe, Argentina \\ $11{ }^{\S}$ Department of Chemistry and Pharmacy, Friedrich-Alexander University Erlangen-Nuremberg, Egerlandstrasse 1, 91058 Erlangen, \\ 12 Germany \\ ${ }_{13}{ }^{\perp}$ Dr. Marcelo A. Martí. Departamento de Química Biológica, FCEN, UBA, Ciudad Universitaria, Pab. II, 1428, Buenos Aires, \\ 14 Argentina
}

\section{S Supporting Information}

16 ABSTRACT: The role of NO in biology is well established. 17 However, an increasing body of evidence suggests that azanone 18 (HNO), could also be involved in biological processes, some of 19 which are attributed to NO. In this context, one of the most 20 important and yet unanswered questions is whether and how $21 \mathrm{HNO}$ is produced in vivo. A possible route concerns the 22 chemical or enzymatic reduction of NO. In the present work, 23 we have taken advantage of a selective $\mathrm{HNO}$ sensing method, 24 to show that $\mathrm{NO}$ is reduced to $\mathrm{HNO}$ by biologically relevant 25 alcohols with moderate reducing capacity, such as ascorbate or$$
\text { to NO by the alcohol, coupled to a proton transfer (PCNA }
$$
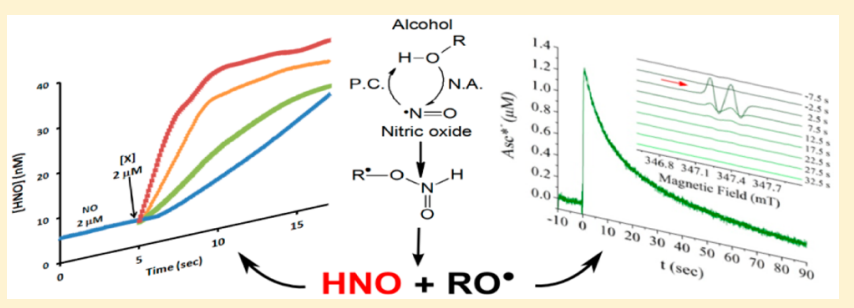

29 After over two decades of intense research, the chemical 30 reactivity of nitric oxide and its key roles in several biological 31 processes, including cardiovascular regulation, immune re32 sponse, and neuronal physiology are, in principle, well 33 established. ${ }^{1-4}$ Azanone ( $\mathrm{HNO} / \mathrm{NO}^{-}$), also called nitroxyl, is 34 the one electron reduction product of $\mathrm{NO}$ and its reactivity and 35 biological relevance are currently under intense debate. ${ }^{5-8}$ It 36 dimerizes rapidly $\left(k_{\mathrm{dim}}=8 \times 10^{6} \mathrm{M}^{-1} \mathrm{~s}^{-1}\right)$, ${ }^{9}$ which limits its 37 concentration and lifetime in the solution. Moreover, HNO 38 reacts quickly with its sibling $\mathrm{NO}\left(k=5.6 \times 10^{6} \mathrm{M}^{-1} \mathrm{~s}^{-1}\right)^{10}$ and 39 at a moderate rate $\left(k=3 \times 10^{3} \mathrm{M}^{-1} \mathrm{~s}^{-1}\right)$ with oxygen.,11,12

$40 \mathrm{HNO}$ signaling is distinct to that of NO: HNO reacts mainly 41 with thiols $^{8,13}$ and heme Fe(III) centers. ${ }^{14,15}$ Unlike NO, HNO 42 activates HNO-TRPA1-CGRP signaling cascade for the 43 regulation of blood pressure and control of cardiac contrac44 tility. 5 The lack of certainty concerning its endogenous 45 production is directly related to its elusive nature and the 46 difficulties surrounding unequivocal and quantitative detection, 47 especially when $\mathrm{NO}$ is present.
In the past decade several methods ${ }^{16-23}$ have been 48 developed allowing detection and quantification of azanone 49 with discrimination from $\mathrm{NO}$ and other reactive nitrogen and 50 oxygen species, RNOS. These methods include chemical 51 trapping and HPLC product characterization, ${ }^{17} \mathrm{UV}-$ vis, ${ }^{19-21}{ }_{52}$ and fluorescence ${ }^{22,24-26}$ detection and electrochemical detec- 53 tion. $^{27-29}$ In particular, our group has developed both a UV- 54 vis trapping-based detection method that uses manganese 55 porphyrins $(\mathrm{MnP})$ and an azanone sensing electrode that is 56 able to provide time-resolved quantification of $\mathrm{HNO}$ at the low 57 nanomolar level. ${ }^{21,28}$

In a broader sense, the biological relevance of nitroxyl has at 59 least two important aspects. The first concerns the studies of 60 the pharmacological effects of HNO and the elucidation of the 61 similarities with and the differences from NO. ${ }^{30-34}$ The second 62 is related to the possibility of its endogenous production as a 63 biologically relevant messenger, ${ }^{31}$ an intermediate metabolite, 64 or an undesired enzymatic side product. ${ }^{35-38}$ In this context, 65

Received: December 10, 2014 
66 several in vivo azanone sources have been proposed. For 67 example, HNO production could result from the activity of 68 nitric oxide synthase (NOS) in the absence of the redox 69 cofactor tetrahydrobiopterin. ${ }^{36,38-41}$ Another well established 70 in vitro enzymatic azanone source relies on the oxidation of 71 hydroxylamine and other amino alcohols. Several groups have 72 shown that this reaction can be catalyzed by heme-proteins like 73 peroxidases, catalases, or even myoglobin. ${ }^{17,42}$ On the other 74 hand, chemical (nonenzymatic), biologically compatible routes 75 to HNO have been, to our knowledge, much less pursued. ${ }^{31,43}$ 76 The most direct route, chemical reduction of NO, has been 77 historically discarded, possibly due to the reduction potential of $78-0.8 \mathrm{~V}$ for the $\left(\mathrm{NO} /{ }^{3} \mathrm{NO}^{-}\right)$couple, which is outside the 79 biological range. However, at physiological $\mathrm{pH},{ }^{1} \mathrm{HNO}$ is 80 expected to be the main species $\left(\mathrm{p} K_{\mathrm{a}}=11.4\right),{ }^{9}$ displaying an 81 estimated $E^{\circ}\left(\mathrm{NO}, \mathrm{H}^{+} /{ }^{1} \mathrm{HNO}\right) \approx-0.14 \mathrm{~V} .{ }^{9,44}$ Moreover, it is 82 important to note that the reduction of $\mathrm{NO}$ to $\mathrm{HNO}$ (reaction 83 1) could be driven forward by coupling with subsequent 84 thermodynamically favorable reactions, such as $\mathrm{N}_{2} \mathrm{O}$ produc85 tion (reaction 2) or reactions between radical intermediates 86 (reaction 3 ).

$$
\begin{array}{ll}
{ }_{87} \mathrm{NO}+\mathrm{ROH} \rightarrow \mathrm{RO}^{\bullet}+\mathrm{HNO} \\
{ }_{88} & 2 \mathrm{NO}+\mathrm{HNO} \rightarrow \mathrm{N}_{2} \mathrm{O}+\mathrm{NO}_{2}{ }^{-}+\mathrm{H}^{+} \\
& \\
{ }_{89} & \mathrm{RO}^{\bullet}+\mathrm{NO} \rightarrow \text { RONO }
\end{array}
$$

90 Interestingly, our recent results showed that HNO can be 91 produced in vivo by the reaction of $\mathrm{NO}^{5}$ or the nitrosyl 92 species $^{30,45,46}$ with $\mathrm{H}_{2} \mathrm{~S}\left(E^{\circ \prime}\left(\mathrm{S}^{\bullet-}, 2 \mathrm{H}^{+} / \mathrm{H}_{2} \mathrm{~S}\right)=E^{\circ \prime}\left(\mathrm{S}^{\bullet-}, \mathrm{H}^{+} /\right.\right.$ $\left.93 \mathrm{HS}^{-}\right)=0.92 \mathrm{~V}$ at $\left.\mathrm{pH} 7\right) .^{45}$ Also noteworthy, are several older 94 works which showed that $\mathrm{NO}$ rebinds with generated $\mathrm{H}^{\bullet}$ to 95 yield azanone. $^{47-50}$

96 In this work we demonstrate that NO can actually be 97 reduced to azanone by several biologically relevant compounds 98 bearing the $-\mathrm{OH}$ functional group resulting in a novel potential 99 pathway for endogenous production of HNO.

\section{EXPERIMENTAL SECTION}

101 Reagents. Mn(III) 5,10,15,20-tetrakis(4-carboxyphenyl)102 porphyrinate was purchased from Frontier Scientific and used as 103 received. All reagents were purchased from Sigma-Aldrich and used as 104 received. Trioxodinitrate $\left(\mathrm{N}_{2} \mathrm{O}_{3}{ }^{2-}\right)$ was synthesized according to 105 published literature procedures. ${ }^{29,51,52}$ Milli-Q grade water was used in 106 all experiments; nitrogen and argon of high purity were used for 107 anaerobic experiments. NO was generated anaerobically by dropwise 108 addition of degassed water to a mixture of $4 \mathrm{~g}$ of $\mathrm{NaNO}_{2}, 8.5 \mathrm{~g}$ of $109 \mathrm{FeSO}_{4}$, and $8.5 \mathrm{~g}$ of $\mathrm{NaBr}$. The so-produced $\mathrm{NO}$ was passed through a $110 \mathrm{NaOH}$ solution to remove higher oxides and bubbled into degassed 111 water in order to get a saturated solution of $\mathrm{NO}([\mathrm{NO}]=2 \mathrm{mM})$.

112 Optical Absorbance. Measurements were recorded using an 113 HP8453 spectrophotometer in $1 \mathrm{~cm}$ path-length quartz cuvette and 114 using as blank the respective buffer solutions. All experiments were

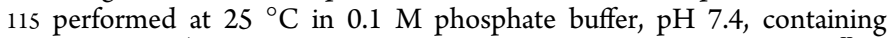
116 DPTA $10^{-4} \mathrm{M}$ to avoid interferences or undesired reactions by $\mathrm{Cu}^{\mathrm{II}}$ or 117 other divalent cations. We also checked that all reactions were 118 unaffected by the irradiation of the sample with the light source of the 119 spectrometer.

120 Infrared Spectrometry. Spectra from 400 to $4000 \mathrm{~cm}^{-1}$ with 1 $121 \mathrm{~cm}^{-1}$ resolution were recorded with a research series Thermo Nicolet 122 FTIR spectrophotometer. All gas phase IR spectra were recorded using 123 an $8 \mathrm{~cm}$ path length gas cell with $\mathrm{NaCl}$ windows. The IR spectrum of 124 the $\mathrm{N}_{2} \mathrm{O}$ present was quantified using calibration curves for the 125 absorption bands showing peaks at 2212 and $2236 \mathrm{~cm}^{-1}$ for the $\mathrm{P}$ and $126 \mathrm{R}$ branches, respectively. ${ }^{53}$ Under these conditions nitrous oxide 127 signals for each injection were compared to a calibration curve prepared by injecting samples of $\mathrm{N}_{2} \mathrm{O}$ produced in situ by $\mathrm{NO}_{2}-128$ BSHA decomposition. ${ }^{29}$ The detection limit for $\mathrm{N}_{2} \mathrm{O}$ in the present 129 conditions was $0.5 \mu$ moles.

Amperometry. Measurements of HNO concentration were 131 carried out with our previously described method based on a three- 132 electrode system consisting of platinum counter electrode, $\mathrm{Ag} / \mathrm{AgCl} 133$ reference electrode, and a gold working electrode modified with a 134 monolayer of cobalt porphyrin with 1-decanethiol covalently attached. 135 The method has been demonstrated to be specific for HNO, showing 136 no interference or spurious signal due to the presence of $\mathrm{NO}, \mathrm{O}_{2}, 137$ $\mathrm{NO}_{2}{ }^{-}$, and other RNOS. ${ }^{27,28,53}$ Signal recording was performed with a 138 TEQ 03 potentiostat.

In a typical experiment, 1.2 to 24 pmoles of $\mathrm{ROH}(0.2$ to $4 \mu \mathrm{M}) 140$ were added to $1.2 \mu$ moles of $\mathrm{NO}$ dissolved in $6 \mathrm{~mL}(0.2 \mathrm{mM})$ of 141 degassed distilled water containing $0.6 \mu$ moles of DPTA (or EDTA) at 142 room temperature (r.t.) under Ar atmosphere (or vice versa). For each 143 case, we also confirmed that the maximum used concentrations $(0.2144$ $\mathrm{mM}$ ) of $\mathrm{NO}$, and all $\mathrm{H}^{\bullet}$ donors produced a very small signal that can 145 be disregarded. We have also performed the reaction of NO with 146 $\mathrm{AscH}^{-}$in an oxygen-free glovebox. In this case, water was 147 deoxygenated by distillation under nitrogen atmosphere after addition 148 of sodium dithionite. The results were very similar to those obtained 149 with degassed water (Supporting Information, Figure SI3B).

Ion Chromatography. Measurements were recorded using a 151 DIODEX DX-100 system, with an AS4A-SC $(4 \mathrm{~mm} \times 250 \mathrm{~mm}) 152$ column and an AG4A-SC guard column. The carrier was $\mathrm{CO}_{3}{ }^{2-} / 153$ $\mathrm{HCO}_{3}{ }^{-} 1.8 / 1.7 \mathrm{mM}$, with a flow rate of $2 \mathrm{~mL} / \mathrm{min}$

EPR Measurements. Solutions and buffers were prepared using 155 high purity reagents and milli- $Q$ grade water. All glassware was 156 previously washed with $\mathrm{HNO}_{3}$ and abundant milli-Q water and 157 silicone tubing and plastic syringes were used to transfer solutions. 158 Diethylene triamine pentaacetic acid (DTPA) (0.5 mM) and/or 159 ethylene diamine tetracetic acid (EDTA) $(8 \mathrm{mM})$ were used as 160 chelating agents to remove possible traces of catalytic metal ions. $\mathrm{O}_{2} 161$ was eliminated from all solutions through vacuum-Ar cycles and a 162 positive $\mathrm{Ar}$ pressure was maintained by bubbling $\mathrm{Ar}$ gas on the 163 solutions throughout all handling.

For ascorbate anion, time scan experiments at a fixed magnetic field 165 were also performed. The field $\mathbf{B}_{0}$ was chosen as the maximum of the 166 low-field peak corresponding to the ascorbyl radical anion doublet. 167 These experiments were performed with $1 \mathrm{G}$ modulation amplitude, 168 $6.33 \mathrm{~mW}$ microwave power, and a conversion time of $20 \mathrm{~ms}$. 169

Computational Methods. To determine the reaction mechanism 170 we performed DFT calculations using the Gaussian 98 software 171 package. All involved species were optimized at the B3LYP level using 172 6-31 G(d,p) for all atoms using water (polarizable continuum model- 173 PCM) in order to take into account solvation effects.

Mass Spectrometry. MS experiments were performed on maXis 175 (Bruker Daltonics) ultrahigh resolution electron spray ionization time- 176 of-flight mass spectrometer equipped with cryospray ionization 177 module (Bruker Daltonics). Into $100 \mu \mathrm{M}$ ascorbate solution in $80 \% 178$ acetonitrile/20\% $10 \mathrm{mM}$ ammonium carbonate buffer $\mathrm{pH}$ 7.4, $500 \mu \mathrm{M} 179$ $\mathrm{NO}$ was added, and the reaction mixture was sprayed at $-20{ }^{\circ} \mathrm{C} .180$ Spectra were recorded over $15 \mathrm{~min}$ time.

Cell Experiments. Bovine Aorta Endothelial cell (BAEC, CLS Cell 182 Lines Service GmbH, Germany) were grown in Ham's F12 medium 183 supplemented with $2 \mathrm{mM}$ L-glutamine and $10 \%$ fetal bovine serum at 184 $37^{\circ} \mathrm{C}$ and $5 \% \mathrm{CO}_{2}$. Cells were loaded with CuBOT1 and fluorescence 185 was recorded as previously described. ${ }^{25,45}$ RAW 264.7 (mouse 186 monocyte macrophage) from ECACC (Salisbury, UK) were grown 187 in DMEM (Sigma-Aldrich, USA, cat. no. D5546) cell medium 188 supplemented with $2 \mathrm{mM}$ L-glutamine (Sigma-Aldrich, USA), $10 \% 189$ FBS (Sigma-Aldrich, USA), 1\% penicillin-streptomycin (Sigma- 190 Aldrich, USA), and $1 \%$ nonessential amino acid solution (Sigma- 191 Aldrich, USA) in T-75 cell culture flask at $5 \% \mathrm{CO}_{2}$ and at $37^{\circ} \mathrm{C}$. Cells 192 were stimulated with $1 \mu \mathrm{g} / \mathrm{mL}$ LPS (Sigma-Aldrich, USA) overnight 193 and next day mechanically detached, washed once with HBSS with 194 $\mathrm{Ca}^{2+}$ and $\mathrm{Mg}^{2}$, and used immediately for analysis. We used $1 \times 10^{6} 195$ cells per sample in HBSS with $\mathrm{Ca}^{2+}$ and $\mathrm{Mg}^{2+}$ supplemented with 196 different concentration of FBS (fetal bovine serum) up to 5\%. The 197 
198 temperature of the HBSS w/o $\mathrm{Ca}^{2+}$ and $\mathrm{Mg}^{2}$ used in measurement 199 experiments was $37^{\circ} \mathrm{C}$.

\section{RESULTS AND DISCUSSION}

201 Aromatic Alcohols and Ascorbate React with NO to 202 Produce HNO. Our first approach to determine the possible 203 production of $\mathrm{HNO}$ from the reaction of NO with aliphatic or 204 aromatic alcohols was performed by measuring the conversion 205 of $\mathrm{Mn}(\mathrm{III}) \mathrm{TCPP}$ to $\{\mathrm{MnNO}\}^{6}$ (Enemark-Feltham notation) 206 using UV-vis spectroscopy (see Supporting Information for 207 more details). ${ }^{54}$ Figure SIIA shows the absorbance changes 208 obtained after mixing NO solution with ascorbate ( $\mathrm{AscH}-$ ), 209 the predominant species under the reaction conditions. These 210 changes are characteristic for the reaction between $\mathrm{Mn}(\mathrm{III})$ 211 porphyrins and $\mathrm{HNO}$, with the consequent formation of $212\{\mathrm{MnNO}\}^{62}{ }^{21}$ Since this $\mathrm{Mn}(\mathrm{III})$ porphyrin reacts neither with $213 \mathrm{NO}^{21}$ nor with ascorbate ${ }^{55}$ (see control experiments in 214 Supporting Information, Figure SI1 and SI2) these results 215 strongly suggest $\mathrm{HNO}$ production. Similar results were 216 obtained with hydroquinone $(\mathrm{HQ})$, tyrosine $(\mathrm{Y})$, and phenol $217(\mathrm{PhOH})$, although the reaction rates varied significantly (see 218 Table 1). No reaction was observed with nonaromatic alcohols

Table 1. Amounts of $\mathrm{N}_{2} \mathrm{O}$ and Nitrite Obtained for the Reactions of $\mathrm{H}^{\bullet}$ Donors with NO, and the Corresponding $k_{\text {eff }}$

$\begin{array}{cccccc}\text { compound }^{a} & \begin{array}{c}k_{\text {eff }} \\ \left(\mathrm{M}^{-1} \mathrm{~s}^{-1}\right)^{b}\end{array} & \begin{array}{c}\mathrm{NO}_{2}^{-} \\ (\mu \mathrm{mol})^{c}\end{array} & \begin{array}{c}\mathrm{N}_{2} \mathrm{O} \\ (\mu \mathrm{mol})^{c}\end{array} & \begin{array}{c}\mathrm{N}_{2} \mathrm{O} \\ \text { yield }^{c}\end{array} & \begin{array}{c}\text { org. prod. } \\ \text { yield }^{d}\end{array} \\ \mathrm{AscH}^{-} & \begin{array}{l}8.0 \pm 0.5 \\ (43 \pm 15)\end{array} & 20 & 16 & 50 \% & >95 \% \\ \mathrm{HQ} & \begin{array}{l}(4.1 \pm 0.4 \\ \mathrm{HQ}\end{array} & 11 & 9 & 30 \% & >95 \% \\ \mathrm{PhOH} & 3.2 \pm 0.4 & 8 & 6 & 20 \% & \sim 90 \% \\ \mathrm{Y} & 0.9 \pm 0.4 & 5 & 4 & 10 \% & \sim 30 \%\end{array}$

${ }^{a}$ No reaction was detected when methanol, D-mannitol or malic acid were used. ${ }^{b}$ Determined from the slope of the electrode signal. Between parentheses, determined by EPR, see Supporting Information for details. ${ }^{c}$ After $24 \mathrm{~h}$, based on the initial amount of NO $(100 \mu \mathrm{mol})$. ${ }^{d}$ Dehydroascorbate (DHA), benzoquinone (BQ), $p-\mathrm{Ph}(\mathrm{OH})-\mathrm{NO}$, and $o$-Y-NO respectively, based on $17 \mu \mathrm{mol}$ (initial amount).

219 like methanol, D-mannitol, or malic acid. The second approach 220 used to determine HNO production relied on the recently 221 developed HNO selective electrode, which allows time-resolved 222 nanomolar detection. ${ }^{27-29,53}$ In Figure 1 we present the 223 amperometric signal versus initial time plot after the addition 224 of each alcohol $(2 \mu \mathrm{M})$ to an anaerobic aqueous solution of $225 \mathrm{NO}(0.2 \mathrm{mM})$. The increase in the current following the 226 addition of the alcohol clearly proves the HNO formation. As 227 expected for a bimolecular reaction, the signal peak, which 228 reflects the HNO concentration, ${ }^{28}$ is linearly dependent on 229 both $\mathrm{AscH}^{-}$and $\mathrm{NO}$ concentrations (Supporting Information, 230 Figure SI3).

231 Figure 2A and Supporting Information, Figure SI3C show 232 that $v_{\mathrm{i}}$ (initial rate) versus $[\mathrm{ROH}]$ and $[\mathrm{NO}]$ plots are linear. 233 From the slope of these plots an effective bimolecular reaction 234 rate constant $\left(k_{\text {eff }}\right)$, corresponding to reaction 1 can be 235 obtained.

$$
v=k_{\text {eff }}[\mathrm{ROH}][\mathrm{NO}]
$$

236 The resulting $k_{\text {eff }}$ are reported in Table 1 , and the data show 237 that both diols ( $\mathrm{HQ}$ and $\mathrm{AscH}^{-}$) react ca. 5-10 times faster 238 than phenols, with $\mathrm{AscH}^{-}$being the fastest.

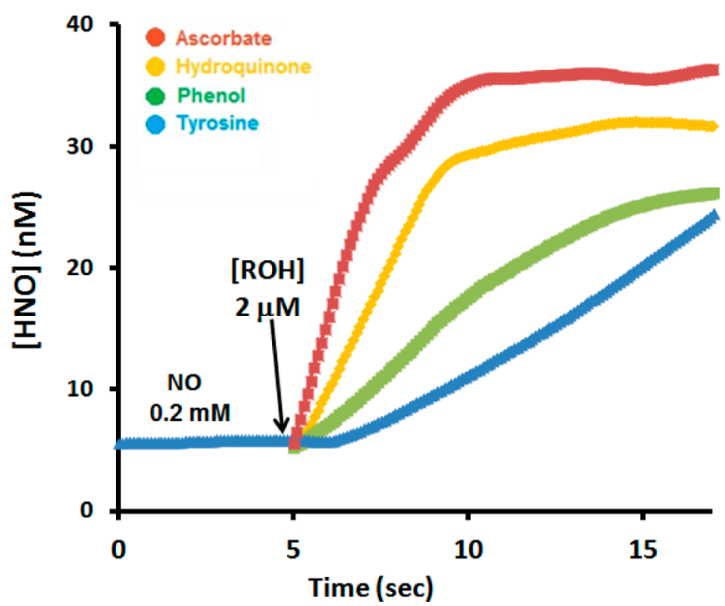

Figure 1. Amperometric signal vs initial time plot after the addition of $2 \mu \mathrm{M} \mathrm{ROH}$ to an anaerobic aqueous solution of $\mathrm{NO}(0.2 \mathrm{mM}): y$-axis, [HNO] after calibration. $\mathrm{ROH}=($ red $) \mathrm{AscH}^{-}$; (orange) $\mathrm{HQ}_{i}$ (green) $\mathrm{PhOH}$; (blue) Y.

On the other hand, Figure 2B and Supporting Information, 239 Figure SI3D show that the $\log \left(v_{\mathrm{i}}\right)$ vs $\log [\mathrm{ROH}]$ and $\log [\mathrm{NO}] 240$ plots are linear with a slope close to 1 , confirming that the 241 reaction is first order in both reactants.

We also tested whether $\mathrm{Fe}(\mathrm{II} / \mathrm{III}), \mathrm{Mn}(\mathrm{II}), \mathrm{Cu}(\mathrm{I} / \mathrm{II})$, or 243 $\mathrm{Co}(\mathrm{II})$ affected HNO production in the described reactions by 244 using the electrochemical nitroxyl sensor. The results confirmed 245 that metal ions do not play any significant role in the 246 production of HNO (see Suppporting Information, Table SI2). 247

EPR Analysis. Since a formal $\mathrm{H}$ atom abstraction from 248 $-\mathrm{OH}$ groups by $\mathrm{NO}$ would produce a free radical species, the 249 reactions were studied by EPR. Ascorbate $(0.2-2 \mathrm{mM}), 250$ hydroquinone $(10 \mathrm{mM})$, and tyrosine $(2 \mathrm{mM})$ solutions were 251 mixed with equal volumes of the NO saturated solutions by 252 simultaneous rapid injection into a quartz flat cell. The 253 presence of dioxygen and metal ions (DPTA or EDTA were 254 used as chelators) was excluded. The first two alcohols 255 produced clearly detectable EPR signals as shown in Figure $3256 \mathrm{f3}$ and Supporting Information, Figure SI5. Tyrosyl radicals were 257 not observed, presumably due to the slower reaction rate 258 between NO and $\mathrm{Y}$ and/or the lower stability of the tyrosyl 259 radical. Figure 3 shows the time dependence of the ascorbyl 260 radical concentration obtained after mixing $\mathrm{AscH}^{-}$and NO. 261

After mixing the reactants, an intense ascorbyl radical signal 262 appears which subsequently decays with a half-life of $4-8$ s. 263 This behavior is consistent with disproportionation of the 264 ascorbyl radical into ascorbate and dehydroascorbate, ${ }^{56}$ and 265 also reaction of ascorbyl with NO to give O-nitrosoascor- 266 bate. ${ }^{43,57}$ For the reaction with HQ (shown in Supporting 267 Information, Figure SI5) similar results were obtained, but the 268 radical signal corresponding to $\mathrm{HQ}^{\bullet}$ increases 6-fold and 269 remains stable for several minutes, slightly decaying after 15270 $\min$. The EPR signals also allow determination of the $k_{\text {eff }}$ for 271 both reactions (shown in Table 1). $k_{\text {eff }}$ values obtained by EPR 272 are in the same order of magnitude as those obtained from the 273 electrochemical data.

The ubisemiquinione EPR signal has been reported during 275 the reaction between NO and truncated ubiquinols, ${ }^{58}$ and the 276 ascorbyl radical has been observed during the reaction between 277 ascorbate and $\mathrm{N}$-acetyl-N-nitrosotryptophan or NO donors 278 under normoxic and oxygen free conditions. ${ }^{43}$ The kinetic 279 
A

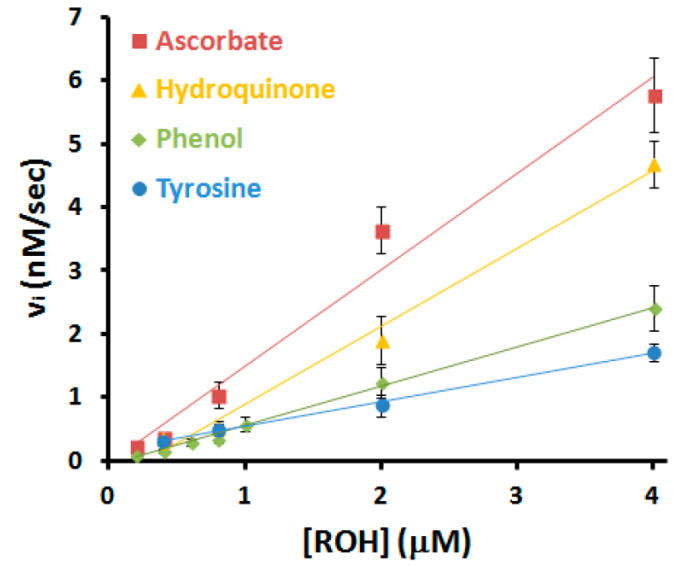

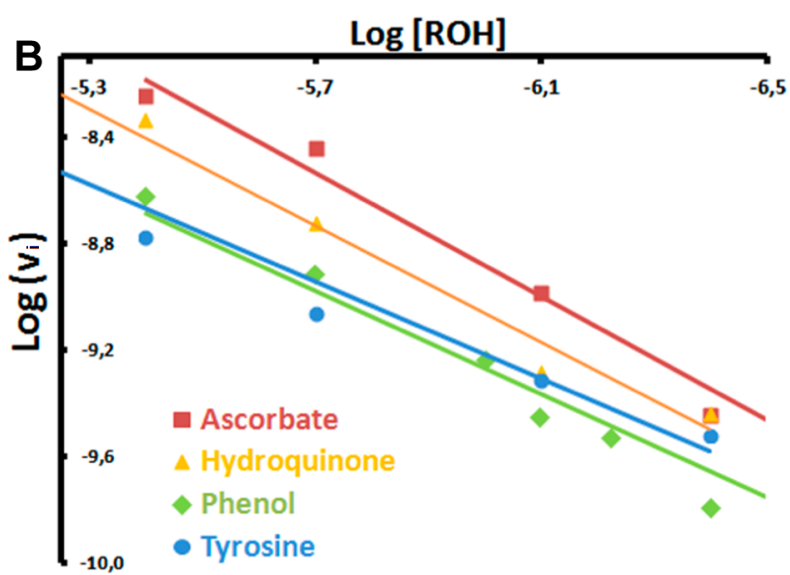

Figure 2. (A) $v_{\mathrm{i}}$ vs $[\mathrm{ROH}]$. (B) $\log \left(v_{\mathrm{i}}\right)$ vs $\log [\mathrm{ROH}]$. [NO $]=0.2 \mathrm{mM}$. $\mathrm{ROH}=\left(\right.$ red) $\mathrm{AscH}^{-}$; (orange) $\mathrm{HQ}_{i}$ (green) PhOH; (blue) Y.

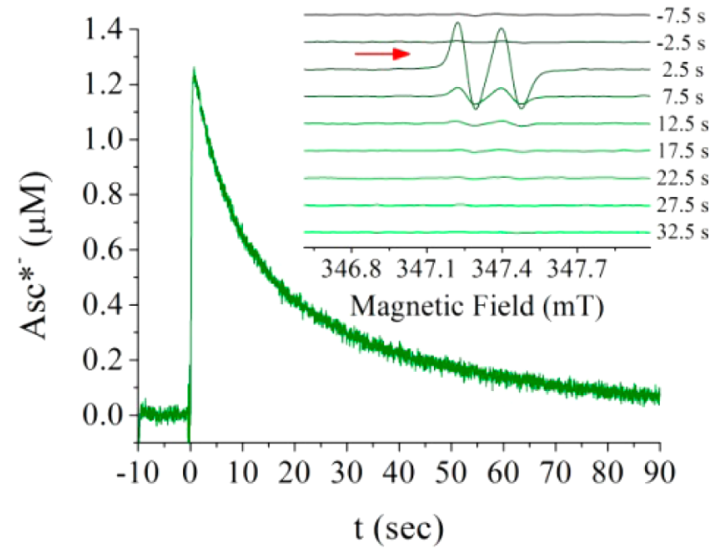

Figure 3. Time dependence of ascorbyl radical concentration. Inset: Consecutive EPR spectra of solutions of ascorbate $(1 \mathrm{mM})$ alone and with NO $(1 \mathrm{mM})$. The arrow indicates beginning of the reaction.

280 analysis of these reactions is detailed in the Supporting 281 Information.

282 End Products Analysis. The initial products of the 283 reaction of NO with the alcohols are unstable and highly 284 reactive radical species. Thus, further reactions are expected to 285 occur. The main sink for $\mathrm{HNO}$ is expected to be its 286 dimerization and/or reaction with $\mathrm{NO},{ }^{10}$ yielding the stable 287 products $\mathrm{N}_{2} \mathrm{O}$ and $\mathrm{NO}_{2}{ }^{-}$. To detect and quantify $\mathrm{N}_{2} \mathrm{O}$ we 288 determined the IR spectra of the reaction chamber headspace. 289 As expected, $\mathrm{NO}$ reaction with $\mathrm{HQ} \mathrm{AscH}^{-}, \mathrm{Y}$, and $\mathrm{PhOH}$ 290 results in the appearance of characteristic $\mathrm{N}_{2} \mathrm{O}$ IR bands at 2912210 and $2230 \mathrm{~cm}^{-1}$ (see Supporting Information, Figure 292 SI7),,$^{53,59}$ and no signal is observed with either reactant alone. 293 The presence of nitrite was confirmed by ion chromatography 294 (see Figure SI8). Moreover, quantification of the relative $\mathrm{N}_{2} \mathrm{O}$ 295 and $\mathrm{NO}_{2}^{-}$yields (Table 1) show that they are formed in a ca. $2961: 1$ ratio, which is consistent with our mechanistic interpreta297 tion (eq 9; vide infra).

298 The $\mathrm{R}-\mathrm{O}^{\bullet}$ radicals are also inherently unstable and thus react 299 further leading to more stable organic closed shell compounds. 300 To determine the corresponding end products for each 301 reaction, we used NMR spectroscopy, IR, UV, and MS 302 spectrometry (see Supporting Information). $\mathrm{AscH}^{-}$yields 303 dehydroascorbate (DHA) as the main end product, formed 304 by ascorbyl radical disproportionation. When studied by cryo305 spray ionization ultrahigh-resolution mass spectrometry, the 306 reaction of $\mathrm{AscH}^{-}$and NO showed MS peaks $(m / z$ 207.0368,
223.0591 and 237.0378, Supporting Information, Figure SI9), 307 which correspond to the first addition of $\mathrm{NO}$ to ascorbate, and 308 second addition of $\mathrm{NO}$ to either first $\mathrm{RO}-\mathrm{NO}^{-}$, or the ascorbyl 309 radical (see below for mechanistic analysis). As postulated by 310 Kirsch, ${ }^{43}$ once the nitrite ester [AscONO $]^{-}$is formed by the 311 reaction of $\mathrm{Asc}^{\bullet-}$ with NO, HNO and DHA can be produced 312 via a radical chain mechanism as shown in eq $4,,^{43}$ eq $5,,^{60}$ and eq 313 $6 .^{43}$

$$
\begin{array}{ll}
{[\mathrm{AscONO}]^{-}+\mathrm{H}^{+} \rightarrow \mathrm{DHA}+\mathrm{HNO}} & \text { (4) } 315 \\
\mathrm{DHA}+\mathrm{Asc}^{-} \rightleftharpoons 2 \mathrm{Asc}^{\bullet-} & \text { (5) } 316 \\
\mathrm{Asc}^{\bullet-}+\mathrm{NO} \rightarrow[\text { AscONO}]^{-} & \text {(6) } 317
\end{array}
$$

HQ yields mainly benzoquinone (BQ), also possibly due to 318 further reaction of the HQ radical with NO. Finally, $\mathrm{PhOH}$ and 319 $\mathrm{Y}$ yield the corresponding products 4-nitrosophenol ( $p$ - 320 $\mathrm{Ph}(\mathrm{OH})-\mathrm{NO})$ and 3-nitrosotyrosine (o-Y-NO), whereas $\mathrm{Y} 321$ also dimerizes to yield dityrosine (see Supporting Information 322 for experimental details); these products are consistent with the 323 presence of $\mathrm{PhO}^{\bullet}$ and $\mathrm{Y}^{\bullet}$ radicals. The lack of EPR signal in 324 these cases possibly arises because of their high reactivity and 325 the presence of the excess of NO, which yields the mentioned 326 products. The yields of the organic products (see Supporting 327 Information for details) are higher than the corresponding $\mathrm{N}_{2} \mathrm{O} 328$ yields, indicating that these compounds are also produced by 329 other routes which do not afford HNO. The formation of 330 nitrosocompounds by reaction of phenols with $\mathrm{NO}$ has been 331 observed before. $^{61}$

Computational Mechanistic Analysis. To get an addi- 333 tional insight into the reaction mechanisms we performed DFT 334 calculations using the Gaussian software package. As an 335 example, the results for $\mathrm{AscH}^{-}$are presented in Scheme 1, $336 \mathrm{sl}$ while the other cases are shown in Supporting Information, 337 Figure SI11. The calculations show that the first step of the 338 reaction between $\mathrm{NO}$ and $\mathrm{AscH}^{-}$is endergonic (by $16 \mathrm{kcal} / 339$ mol) yielding a radical intermediate $\mathrm{RO}-\mathrm{N}(\mathrm{H}) \mathrm{O}^{\bullet}$ (consistent 340 with one of the peaks observed in the mass spectrometer at $\mathrm{m} / z 341$ 207.0368, see Scheme 1 and Supporting Information, Figure 342 SI9). This step can be described as a nucleophilic attack of the 343 ascorbate anion to NO (reaction 7), coupled to proton transfer 344 from the vicinal $-\mathrm{OH}$ moiety or the solvent. Such a mechanism 345 can be described as a proton-coupled nucleophilic attack 346 (PCNA).

$\mathrm{NO}$ binds preferably to $\mathrm{C} 2-\mathrm{O}$, while ascorbate is preferably 348 deprotonated at $\mathrm{C} 3-\mathrm{O}$ (see Scheme 1). At this point it is 349 
Scheme 1. DFT Calculations. Energy Values Reported in $\mathrm{kcal} / \mathrm{mol}$

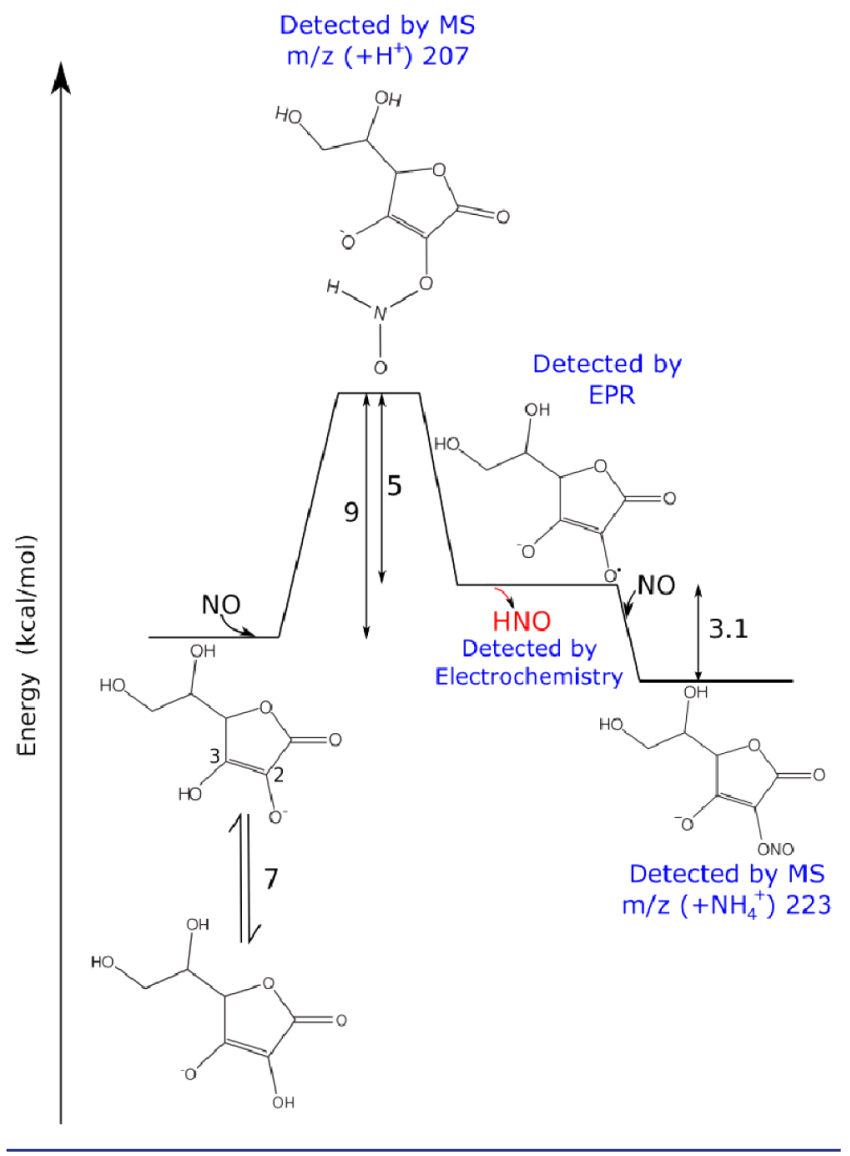

350 difficult to determine whether the NO reacts with one or the 351 other tautomer, with the $\mathrm{OH}$ or $\mathrm{O}^{-}$, and how and when the 352 protons are transferred. However, attack of $-\mathrm{O}^{-}$to $\mathrm{NO}$ seems to 353 be more likely. The $\mathrm{RO}-\mathrm{N}(\mathrm{H}) \mathrm{O}^{\bullet}$ radical intermediate decays 354 to HNO and the ascorbyl radical (reaction 8), which can then 355 react with another $\mathrm{NO}$ to produce a closed shell nitrite ester $o$ 356 nitrosoascorbate (also observed by MS at $\mathrm{m} / z$ 223.0591). 357 Reaction of the radical with the second NO prior to its HNO 358 release, possibly accounts for formation of di-ONO observed by 359 MS ( $m / z$ 237.0378, Supporting Information, Figure SI9g). The $360 \mathrm{O}$-nitrosoascorbate also decays after taking a proton to yield $361 \mathrm{HNO}$ and DHA, as previously observed by Kirsch and co362 workers. $^{57}$

$$
\begin{array}{ll}
363 & \mathrm{Nu}^{-}\left(+\mathrm{H}^{+}\right)+\mathrm{NO}^{\bullet} \rightarrow(\mathrm{Nu}-\mathrm{NH}-\mathrm{O})^{\bullet} \\
364 & (\mathrm{Nu}-\mathrm{NH}-\mathrm{O})^{\bullet} \rightarrow \mathrm{HNO}+(\mathrm{Nu})^{\bullet}
\end{array}
$$

365 A similar mechanism is expected for HQ (see Supporting 366 Information), with two NO molecules reacting with each HQ 367 molecule. For $\mathrm{Y}$ and $\mathrm{PhOH}$, the radical intermediates produced 368 after the addition of $\mathrm{NO}$, formation of the $\mathrm{RO}-\mathrm{N}(\mathrm{H}) \mathrm{O}$ 369 intermediate, and $\mathrm{HNO}$ release also yield the observed nitroso 370 derivatives. More importantly, taking into account the $\mathrm{p} K_{\mathrm{a}}$ of 371 the corresponding alcohol, in these three cases the reaction 372 undoubtedly occurs with a neutral $\mathrm{OH}$ group, where an 373 intramolecular proton rearrangement or solvent-assisted 374 protonation is required. Therefore, in these cases a PCNA is 375 proposed as well.

376 Last but not least, it is important to note that although the 377 first reaction step between NO and alcohol is endergonic, the reaction is driven forward by the subsequent reactions of the 378 initial products ( $\mathrm{HNO}$ and radicals). In fact, $\mathrm{HNO}$ dimerization 379 overcompensates the endergonic $\mathrm{HNO}$ generation resulting in 380 an overall negative free energy balance for the global reaction 9381 (see Scheme 1), which for $\mathrm{AscH}^{-}$is

$$
\mathrm{AscH}^{-}+6 \mathrm{NO} \rightarrow \mathrm{DHA}+2 \mathrm{~N}_{2} \mathrm{O}+2 \mathrm{NO}_{2}{ }^{-}+\mathrm{H}^{+}
$$

The energy associated with the first step, either to yield directly 384 HNO by HAT or an "RON $(\mathrm{H}) \mathrm{O}-$ like" radical intermediate by 385 PCNA, can be considered a minimum estimation of the global 386 reaction barrier. As shown in Table 2, the $\Delta E$ for the first two 387 t2

\begin{tabular}{|c|c|c|c|c|c|c|}
\hline & $\mathrm{p} K_{\mathrm{a}}$ & $\begin{array}{c}E^{\circ \prime}(\mathrm{V}) \\
(\mathrm{pH} 7) \\
\mathrm{RO}^{\circ} \\
\mathrm{H}^{+} / \mathrm{ROH}\end{array}$ & $\begin{array}{c}\Delta E \\
\mathrm{PCNA}^{a}\end{array}$ & $\begin{array}{c}\Delta E \\
\mathrm{HNO} \\
\text { release }^{a}\end{array}$ & $\begin{array}{c}\Delta E \\
\text { step } 1+2^{a}\end{array}$ & global $^{a, c}$ \\
\hline $\mathrm{AscH}^{-}$ & 4.11 & 0.28 & +16 & -5 & +11 & -58 \\
\hline HQ & 10 & 0.10 & +18.5 & 10.5 & +8 & -109 \\
\hline $\mathrm{Y}$ & 10 & 0.91 & +25.4 & +7.4 & +33 & -63 \\
\hline $\mathrm{PhOH}$ & 10 & 0.97 & +25.3 & +12.4 & +37.7 & -70 \\
\hline $\mathrm{MeOH}^{b}$ & 15.5 & - & +19.5 & +33.7 & +53.2 & - \\
\hline
\end{tabular}

Table 2. Ab Initio Calculated Reaction Energies $(\Delta E)$ in $\mathrm{kcal} / \mathrm{mol}$ for PCNA and HNO Release Steps

${ }^{a} \Delta E_{\text {PCM }}^{\circ}(\mathrm{kcal} / \mathrm{mol})$, optimized at the B3LYP level using 6-31 G(d,p) for all atoms using water (PCM: polarizable continuum model); step 1 , PCNA; step 2, HNO release. ${ }^{b}$ HNO was not detected when methanol was used. ${ }^{c}$ Final product was DHA, BQ $p-\mathrm{Ph}(\mathrm{OH}) \mathrm{NO}$, and $o$-YNO, respectively (see SI).

steps (step 1+2) are smaller for $\mathrm{AscH}^{-}$and $\mathrm{HQ}$ which are the 388 faster reactants (Table 1$)$. The largest $\Delta E(+53.2 \mathrm{kcal} / \mathrm{mol})$ is 389 observed for $\mathrm{MeOH}$, which does not react under the tested 390 conditions. The calculated energies for step $1+2$ and for the 391 global reaction are in reasonable agreement with those energies 392 obtained from tabulated redox potentials (Supporting In- 393 formation, Table SI3).

394

To assess the potential role of molecular oxygen on these 395 reactions, we performed the reaction of $\mathrm{AscH}^{-}$and $\mathrm{NO}$ in the 396 presence of controlled amounts of oxygen (Supporting 397 Information, Figures SI2 and SI4). As shown in Figure SI4, 398 the amount of $\mathrm{HNO}$ produced decreases as the relative amount 399 of added $\mathrm{O}_{2}$ is increased. This is a strong indication that $\mathrm{O}_{2} 400$ does not catalyze $\mathrm{HNO}$ formation. Instead, the presence of $\mathrm{O}_{2} 401$ diminishes the observed signal, a fact that can be attributed to 402 its known reaction with either reactant, or even with azanone, 403 as shown in our previous work. ${ }^{28}$

In Vitro Cell Studies. In certain cell types, such as 405 endothelial cells, neuronal cells, and immune cells, vitamin C 406 accumulates to concentrations higher than $1 \mathrm{mM}^{62}$ To analyze 407 whether the described reactions occur under physiological 408 conditions, we used an HNO fluorescence sensor, CuBOT1, to 409 evaluate the intracellular azanone formation. ${ }^{22,24-26}$ Bovine 410 arterial endothelial cells were pretreated with either $1 \mathrm{mM} 411$ $\mathrm{AscH}^{-}$or $1 \mathrm{mM} \mathrm{pBQH} 2$ for $1 \mathrm{~h}$ to increase their intracellular 412 concentration. Cells were washed and then loaded with 413 CuBOT1 to assess the changes in intracellular levels of 414 HNO. The intensity of the fluorescence was compared with 415 basal fluorescence detected in the control (untreated cells). 416 Figure 4A shows a clear increase of the fluorescence with both $417 \mathrm{f} 4$ treatments. In addition we tested the ability of ascorbate to 418 reduce endogenously generated NO from another cell line, 419 RAW 264.7 macrophages. Macrophages were stimulated with 420 lipopolysaccharide(LPS)/interferon gamma to stimulate indu- 421 
A)

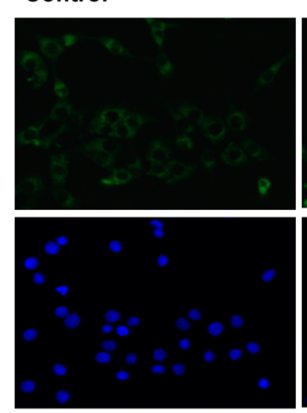

Asch
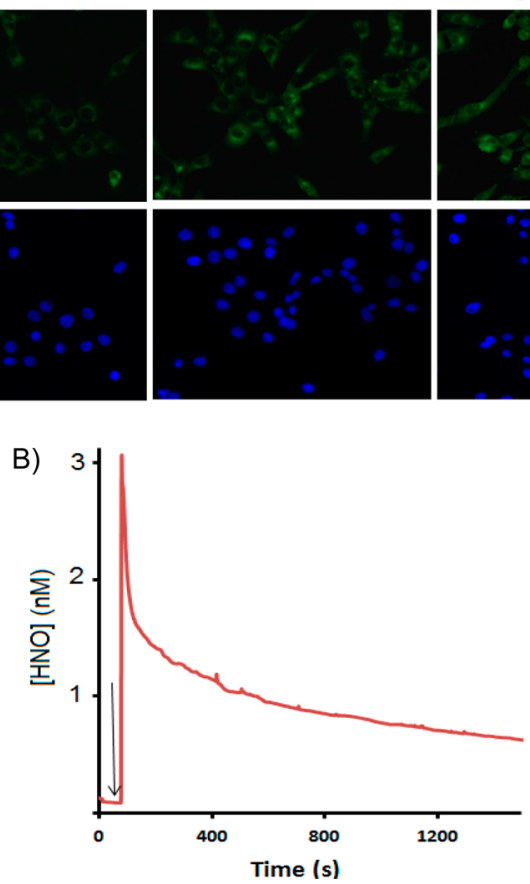

$\mathrm{pBQH}_{2}$

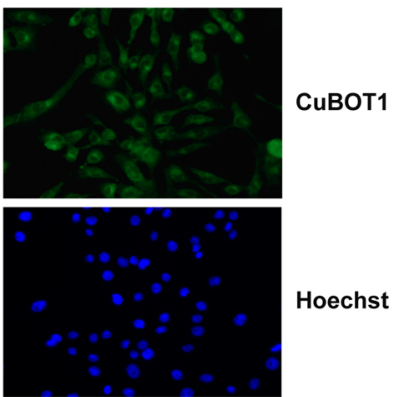

Figure 4. (A) Intracellular HNO formation in bovine arterial endothelial cells as revealed by the HNO fluorescence sensor, CuBOT1. Hoeschst was used to stain the nuclei, showing that there are cells in the control for which the signal is very low, and also that the position of the signal matches the actual cells. (B) HNO formation after the addition of ascorbate to immunostimulated macrophages. The HNO electrode was immersed into a $10^{6}$ cell $/ \mathrm{mL}$ suspension of immunostimulated macrophages in Dulbecco's Modified Eagle's Medium (DMEM). Subsequently 1 mM ascorbate was added, and the current was monitored.

422 cible nitric oxide synthase to produce $\mathrm{NO}$, and the $\mathrm{HNO}$ 423 electrode was immersed in the extracellular medium containing $42410^{6}$ cells $/ \mathrm{mL}$. After the addition of $1 \mathrm{mM}$ ascorbate an 425 immediate rise in the signal was observed, showing clear HNO 426 formation (Figure 4B). No signal was observed when $\mathrm{AscH}^{-}$ 427 was added into cell-free medium.

428 These data strongly suggest that $\mathrm{HNO}$ could be produced in 429 the reaction of $\mathrm{NO}$ and $\mathrm{AscH}^{-}$under physiological conditions.

\section{CONCLUSIONS}

431 The present work provides clear evidence of a possible 432 biochemically relevant HNO source, resulting from the reaction 433 of NO with aromatic or "pseudoaromatic" alcohols such as 434 tyrosine, ascorbic acid, and hydroquinone. Mechanistically, it is 435 clear that the reaction does not involve a simple outer sphere 436 reduction coupled to proton release/uptake, which is 437 thermodynamically unfavorable as evidenced by the alcohol 438 reduction potentials shown in Table 2 .

439 Instead, our data suggest that there is a nucleophilic addition 440 of $\mathrm{ROH} / \mathrm{RO}^{-}$to $\mathrm{NO}$, coupled to a proton transfer (either 441 intramolecular or through the solvent) that results in an RO$442 \mathrm{~N}(\mathrm{H}) \mathrm{O}^{\bullet}$ intermediate, which decays by $\mathrm{O}-\mathrm{N}$ bond cleavage, 443 producing $\mathrm{HNO}$ and the corresponding radical (see Scheme 2 444 and Table 2). The stability of the $\mathrm{RO}^{\bullet}$ radical (bound to HNO

Scheme 2. Proposed Mechanism for HNO Formation by the Reaction of NO with ROH

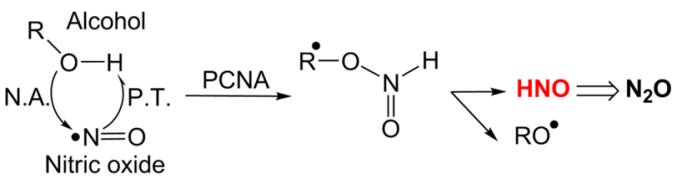

or free), PCNA endergonicity, and the global energy for steps 1445 +2 (Table 2) seems to be the key factor for the reaction to 446 occur, explaining why no reaction is observed for $\mathrm{MeOH}$ or 447 mannitol, and why $\mathrm{AscH}^{-}$and HQ react faster.

448

Beyond the chemical novelty, biological implications are 449 direct. For example, given the known preference for NO 450 partition within the hydrophobic interior of biological 451 membranes ${ }^{63}$ and its physiological role in plant and animal 452 mitochondria, the following picture emerges: ${ }^{64,65}$ under 453 hypoxia, respiratory chain intermediate quinones accumulate 454 and NO production increases, through nitrite reductase activity 455 of myoglobin among others, ${ }^{66}$ creating an ideal opportunity for 456 the presented reaction to take place. In addition, the presented 457 proof of concept for physiological NO conversion to HNO, 458 suggests that it is not unlikely that some of the protective 459 effects assigned to NO, are indeed mediated by its "younger" 460 sibling $\mathrm{HNO},{ }^{67}$ as shown in our recent work. ${ }^{31} 461$

Definitive proof to these hypotheses awaits further studies 462 and opens the way for both potential therapeutic interventions 463 of azanone donors and understanding of endogenous HNO 464 production.

\section{ASSOCIATED CONTENT}

Kinetic analysis, ab initio calculations, mass spectra, EPR, and 468 other experimental details. This material is available free of 469 charge via the Internet at http://pubs.acs.org. 


\section{Notes}

476 The authors declare no competing financial interest.

\section{ACKNOWLEDGMENTS}

478 This work was financially supported by UBA (UBACYT W583 479 and 2010-12), ANPCyT (PICT 2010-2649 and 2010-416), 480 CONICET (PIP1207 and 112-201001-00125), and from the 481 Bunge y Born Foundation. S.A.S. and L.A. thank CONICET for 482 a fellowship grant, NIN, DEB, CDB, MAM, and FAD are 483 members of CONICET. J.M., M.R.F., and I.I.-B acknowledge 484 the support by intramural funds provided by the FAU within 485 the Emerging Field Initiative (Medicinal Redox Inorganic 486 Chemistry).

\section{$487 \square$ REFERENCES}

488 (1) Napoli, C.; Paolisso, G.; Casamassimi, A.; Al-Omran, M.; 489 Barbieri, M.; Sommese, L.; Infante, T.; Ignarro, L. J. J. Am. Coll. 490 Cardiol. 2013, 62, 89.

491 (2) Tonzetich, Z. J.; McQuade, L. E.; Lippard, S. J. Inorg. Chem. 492 2010, 49, 6338.

493 (3) Goodrich, L. E.; Paulat, F.; Praneeth, V. K. K.; Lehnert, N.; 494 Arbor, A. Biochemistry 2010, 6293.

495 (4) Martínez-Ruiz, A.; Cadenas, S.; Lamas, S. Free Radic. Biol. Med. 496 2011, 51, 17.

497 (5) Bruce King, S. Free Radic. Biol. Med. 2013, 55, 1.

498 (6) Irvine, J. C.; Ritchie, R. H.; Favaloro, J. L.; Andrews, K. L.; 499 Widdop, R. E.; Kemp-Harper, B. K. Trends Pharmacol. Sci. 2008, 29, 500601.

501 (7) Flores-Santana, W.; Salmon, D. J.; Donzelli, S.; Switzer, C. H.; 502 Basudhar, D.; Ridnour, L.; Cheng, R.; Glynn, S. A.; Paolocci, N.; 503 Fukuto, J. M.; Miranda, K. M.; Wink, D. A. Antioxid. Redox Signal. $5042011,14,1659$.

505 (8) Miranda, K. M. Coord. Chem. Rev. 2005, 249, 433.

506 (9) Shafirovich, V.; Lymar, S. V. Proc. Natl. Acad. Sci. U.S.A. 2002, 99, 5077340 .

508 (10) Lymar, S. V.; Shafirovich, V.; Poskrebyshev, G. A. Inorg. Chem. $5092005,44,5212$.

510 (11) Miranda, K. M.; Nims, R. W.; Thomas, D. D.; Espey, M. G.; 511 Citrin, D.; Bartberger, M. D.; Paolocci, N.; Fukuto, J. M.; Feelisch, M.; 512 Wink, D. A. J. Inorg. Biochem. 2003, 93, 52.

513 (12) Liochev, S. Free Radic. Biol. Med. 2003, 34, 1399.

514 (13) Bartberger, M. D.; Fukuto, J. M.; Houk, K. N. Proc. Natl. Acad. 515 Sci. U.S.A. 2001, 98, 2194.

516 (14) Ford, P. C. Inorg. Chem. 2010, 49, 6226.

517 (15) Hoshino, M.; Laverman, L.; Ford, P. C. Coord. Chem. Rev. 1999, $518187,75$.

519 (16) Cline, M. R.; Tu, C.; Silverman, D. N.; Toscano, J. P. Free Radic. 520 Biol. Med. 2011, 50, 1274.

521 (17) Reisz, J. A.; Zink, C. N.; King, S. B. J. Am. Chem. Soc. 2011, 133, 52211675 .

523 (18) Donzelli, S.; Espey, M. G.; Flores-Santana, W.; Switzer, C. H.; 524 Yeh, G. C.; Huang, J.; Stuehr, D. J.; King, S. B.; Miranda, K. M.; Wink, 525 D. a. Free Radic. Biol. Med. 2008, 45, 578.

526 (19) Suárez, S. A.; Martí, M. A.; De Biase, P. M.; Estrin, D. a.; Bari, S. 527 E.; Doctorovich, F. Polyhedron 2007, 26, 4673.

528 (20) Dobmeier, K. P.; Riccio, D. A.; Schoenfisch, M. H. Anal. Chem. 529 2008, 80, 1247.

530 (21) Martí, M. A.; Bari, S. E.; Estrin, D. A.; Doctorovich, F. J. Am. 531 Chem. Soc. 2005, 127, 4680.

532 (22) Zhou, Y.; Liu, K.; Li, J.-Y.; Fang, Y.; Zhao, T.-C.; Yao, C. Org. 533 Lett. 2011, 13, 2357.

534 (23) Doctorovich, F.; Bikiel, D.; Pellegrino, J.; Suárez, S. A.; Larsen, 535 A.; Martí, M. A. Coord. Chem. Rev. 2011, 255, 2764.

536 (24) Tennyson, A. G.; Do, L.; Smith, R. C.; Lippard, S. J. Nitric Oxide 537 2006, 26, 1.

538 (25) Rosenthal, J.; Lippard, S. J. J. Am. Chem. Soc. 2010, 132, 5536.
(26) Wrobel, A. T.; Johnstone, T. C.; Liang, A. D.; Lippard, S. J.; 539 Rivera-fuentes, P. J. Am. Chem. Soc. 2014, 136, 4697.

(27) Suárez, S. A.; Fonticelli, M. H.; Rubert, A. A.; de la Llave, E.; 541 Scherlis, D.; Salvarezza, R. C.; Martí, M. A.; Doctorovich, F. Inorg. 542 Chem. 2010, 49, 6955.

(28) Suárez, S.; Bikiel, D.; Wetzler, D.; Martí, M. A.; Doctorovich, F. 544 Anal. Chem. 2013, 85, 10262-10269. 545

(29) Sirsalmath, K.; Suárez, S. A.; Bikiel, D. E.; Doctorovich, F. J. 546 Inorg. Biochem. 2013, 118, 134.

(30) Filipovic, M. R.; Eberhardt, M.; Prokopovic, V.; Mijuskovic, A.; 548 Orescanin-Dusic, Z.; Reeh, P.; Ivanovic-Burmazovic, I. J. Med. Chem. 549 2013, 56, 1499.

(31) Eberhardt, M.; Dux, M.; Namer, B.; Miljkovic, J.; Cordasic, N.; 551 Will, C.; Kichko, T. I.; Roche, J.; de la Fischer, M.; Bikiel, D.; Suárez, S. 552 A.; Dorsch, K.; Leffler, A.; Babes, A.; Lampert, A.; Lennerz, J. K.; 553 Jacobi, J.; Martí, M. A.; Doctorovich, F.; Högestätt, E. D.; Zygmunt, P. 554 M.; Ivanovic-Burmazovic, I.; Messlinger, K.; Reeh, P.; Filipovic, M. R. 555 Nat. Commun. 2014, 5, 4381.

(32) Fukuto, J. M.; Cisneros, C. J.; Kinkade, R. L. J. Inorg. Biochem. 557 2013, 118, 201.

(33) Miranda, K. M.; Paolocci, N.; Katori, T.; Thomas, D. D.; Ford, 559 E.; Bartberger, M. D.; Espey, M. G.; Kass, D. a; Feelisch, M.; Fukuto, J. 560 M.; Wink, D. A. Proc. Natl. Acad. Sci. U.S.A. 2003, 100, 9196.

(34) Paolocci, N.; Saavedra, W. F.; Miranda, K. M.; Martignani, C.; 562 Isoda, T.; Hare, J. M.; Espey, M. G.; Fukuto, J. M.; Feelisch, M.; Wink, 563 D. A.; Kass, D. A. Proc. Natl. Acad. Sci. U.S.A. 2001, 98, 10463.

(35) Adak, S.; Wang, Q.; Stuehr, D. J. J. Biol. Chem. 2000, 275, 565 33554.

(36) Schmidt, H. H. H. W.; Hofmann, H.; Schindler, U.; Shutenko, 567 Z. S.; Cunningham, D. D.; Feelisch, M. Proc. Natl. Acad. Sci. U.S.A. 568 1996, 93, 14492.

(37) Feelisch, M.; Te Poel, M.; Zamora, R.; Deussen, A.; Moncada, S. 570 Nature 1994, 368, 62.

(38) Rousseau, D. L.; Li, D.; Couture, M.; Yeh, S.-R. J. Inorg. Biochem. 572 2005, 99, 306.

(39) Ishimura, Y.; Gao, Y. T.; Panda, S. P.; Roman, L. J.; Masters, B. 574 S. S.; Weintraub, S. T. Biochem. Biophys. Res. Commun. 2005, 338, 543. 575 (40) Sabat, J.; Egawa, T.; Lu, C.; Stuehr, D. J.; Gerfen, G. J.; 576 Rousseau, D. L.; Yeh, S.-R. J. Biol. Chem. 2013, 288, 6095. (41) Li, D.; Kabir, M.; Stuehr, D. J.; Rousseau, D. L.; Yeh, S.-R. J. Am. 578 Chem. Soc. 2007, 129, 6943.

(42) Donzelli, S.; Graham, M.; Flores-Santana, W.; Switzer, C. H.; 580 Yeh, G. C.; Huang, J.; Stuehr, D. J.; King, S. B.; Miranda, K. M.; Wink, 581 D. A.; Espey, M. G. Free Radic. Biol. Med. 2008, 45, 578.

(43) Kytzia, A.; Korth, H.; Sustmann, R.; Groot, H.; De Kirsch, M. 583 Chem.-Eur. J. 2006, 8786.

(44) Armstrong, D. A.; Huie, R. E.; Lymar, S.; Koppenol, W. H.; 585 Merényi, G.; Neta, P.; Stanbury, D. M.; Steenken, S.; Wardman, P. 586 Bioinorg. React. Mech. 2013, 9, 59.

(45) Filipovic, M. R. M.; Miljkovic, J. L. J.; Nauser, T.; Royzen, M.; 588 Klos, K.; Shubina, T.; Koppenol, W. H.; Lippard, S. J.; Ivanović- 589 Burmazović, I.; Ivanovic, I. J. Am. Chem. Soc. 2012, 134, 12016.

(46) Miljkovic, J. L.; Kenkel, I.; Ivanović-Burmazović, I.; Filipovic, M. 591 R. Angew. Chem., Int. Ed. 2013, 52, 12061.

(47) Clyne, M. A. A.; Thrush, B. A. Trans. Faraday Soc. 1961, 57, 593 1305.

(48) Cashion, J. K.; Polanyi, J. C. J. Chem. Phys. 1959, 30, 317. (49) Strausz, O. P.; Gunning, H. E. Trans. Faraday Soc. 1964, 60, 347. 596 (50) Kohout, F. C.; Lampe, F. W. J. Am. Chem. Soc. 1965, 87, 5795. 597 (51) Miranda, K. M.; Paolocci, N.; Katori, T.; Thomas, D. D.; Ford, 598 E.; Bartberger, M. D.; Espey, M. G.; Kass, D. A.; Feelisch, M.; Fukuto, 599 J. M.; Wink, D. A. Proc. Natl. Acad. Sci. U.S.A. 2003, 100, 9196.600

(52) Porcheddu, A.; De Luca, L.; Giacomelli, G. Synlett 2009, 13, 601 2149.

(53) Heinecke, J. L.; Khin, C.; Pereira, J. C. M.; Suárez, S. A.; Iretskii, 603 A. V.; Doctorovich, F.; Ford, P. C. J. Am. Chem. Soc. 2013, 135, 4007. 604

(54) Álvarez, L.; Suarez, S. A.; Bikiel, D. E.; Reboucas, J. S.; Batinić- 605 Haberle, I.; Martí, M. A.; Doctorovich, F. Inorg. Chem. 2014, 53, 7351. 606 
607 (55) Spasojevic, I.; Batini-Haberle, I.; Fridovich, I. Nitric Oxide 2000, $6084,526$.

609 (56) Benon, H. J.; Bielski, A.; Allen, O.; Schwarz, H. A. J. Am. Chem. 610 Soc. 1981, 103, 3516.

611 (57) Kirsch, M.; Büscher, A.-M.; Aker, S.; Schulz, R.; de Groot, H. 612 Org. Biomol. Chem. 2009, 7, 1954.

613 (58) Poderoso, J. J.; Carreras, M. C.; Schöpfer, F.; Lisdero, C. L.; 614 Riobó, N. A.; Giulivi, C.; Boveris, A. D.; Boveris, A.; Cadenas, E. Free 615 Radic. Biol. Med. 1999, 26, 925.

616 (59) Heinecke, J.; Ford, P. C. Coord. Chem. Rev. 2010, 254, 235.

617 (60) J. van der, Zee; P. J. A. van den, Broek Free Radic. Biol. Med. 618 1998, 25, 282.

619 (61) Yenes, S.; Messeguer, A. Tetrahedron 1999, 55, 14111.

620 (62) May, J. M. Free Radic. Biol. Med. 2000, 28, 1421.

621 (63) Liu, X.; Miller, M. J.; Joshi, M. S.; Thomas, D. D.; Lancaster, J. 622 R. Proc. Natl. Acad. Sci. U.S.A. 1998, 95, 2175.

623 (64) Kamga, C.; Krishnamurthy, S.; Shiva, S. Nitric Oxide 2012, 26, 624251.

625 (65) Gupta, K. J.; Igamberdiev, A. U.; Manjunatha, G.; Segu, S.; 626 Moran, J. F.; Neelawarne, B.; Bauwe, H.; Kaiser, W. M. Plant Sci. 2011, $627181,520$.

628 (66) Shiva, S.; Huang, Z.; Grubina, R.; Sun, J.; Ringwood, L. A.; 629 MacArthur, P. H.; Xu, X.; Murphy, E.; Darley-Usmar, V. M.; Gladwin, 630 M. T. Circ. Res. 2007, 100, 654.

631 (67) Chouchani, E. T.; Methner, C.; Nadtochiy, S. M.; Logan, A.; 632 Pell, V. R.; Ding, S.; James, A. M.; Cochemé, H. M.; Reinhold, J.; 633 Lilley, K. S.; Partridge, L.; Fearnley, I. M.; Robinson, A. J.; Hartley, R. 634 C.; Smith, R. A. J.; Krieg, T.; Brookes, P. S.; Murphy, M. P. Nat. Med. $6352013,19,753$. 